\title{
Identification of anti-inflammatory constituents in Hypericum perforatum and Hypericum gentianoides extracts using RAW 264.7 mouse macrophages
}

\author{
Nan Huanga,b,c, Ludmila Rizshsky ${ }^{a, d}$, Cathy Hauck ${ }^{a, c}$, Basil J. Nikolau ${ }^{a, d}$, Patricia A. \\ Murphy ${ }^{\mathrm{a}, \mathrm{c}}$, and Diane F. Birt ${ }^{\mathrm{a}, \mathrm{b}, \mathrm{c},{ }^{*}}$ \\ Nan Huang: huangnan@iastate.edu; Ludmila Rizshsky: ludmilar@iastate.edu; Cathy Hauck: cchauck@iastate.edu; Basil \\ J. Nikolau: dimmas@iastate.edu; Patricia A. Murphy: pmurphy@iastate.edu \\ aThe Center for Research on Botanical Dietary Supplements, lowa State University, Ames, lowa, \\ 50011 \\ bInterdepartmental Graduate Program in Nutritional Sciences, lowa State University, Ames, lowa, \\ 50011 \\ 'Department of Food Science and Human Nutrition, lowa State University, Ames, lowa, 50011 \\ ${ }^{\mathrm{d} D e p a r t m e n t}$ of Biochemistry, Biophysics and Molecular Biology, lowa State University, Ames, \\ lowa, 50011
}

\section{Abstract}

Hypericum perforatum (St. John's wort) is an herb widely used as supplement for mild to moderate depression. Our prior studies revealed synergistic anti-inflammatory activity associated with 4 bioactive compounds in a fraction of $H$. perforatum ethanol extract. Whether these 4 compounds also contributed to the ethanol extract activity was addressed in the research reported here. Despite the popularity of $H$. perforatum, other Hypericum species with different phytochemical profiles could have their anti-inflammatory potentials attributed to these or other compounds. In the current study, ethanol extracts of different Hypericum species were compared for their inhibitory effect on LPS-induced prostaglandin E2 (PGE2) and nitric oxide (NO) production in RAW 264.7 mouse macrophages. Among these extracts, those made from $H$. perforatum and $H$. gentianoides demonstrated stronger overall efficacy. LC-MS analysis indicated the 4 compounds in $H$. perforatum extract and pseudohypericin in all active fractions. The 4 compounds accounted for a significant part of the extract's inhibitory activity on PGE2, NO, tumor necrosis factor- $\alpha$ (TNF- $\alpha$ ), and interleukin-1 $\beta$ (IL-1 $\beta$ ) in RAW 264.7 as well as peritoneal macrophages. Pseudohypericin was the most important contributor of the anti-inflammatory potential among the 4 compounds. The lipophilic fractions of $H$. gentianoides extract, which did not contain the previously identified active constituents, decreased PGE2 and NO potently. These fractions were rich in acylphloroglucinols, including uliginosin A that accounted for a proportion of the anti-inflammatory activity observed with the active fractions. Overall, the current study revealed a different group of major anti-inflammatory constituents in $\mathrm{H}$. gentianoides, while showing that a previously identified 4 compounds combination was important for $H$. perforatum's anti-inflammatory potential.

\footnotetext{
(C) 2011 Elsevier Ltd. All rights reserved.

*To whom correspondence should be addressed: Tel: (515) 294-9873.dbirt@iastate.edu.
}

Publisher's Disclaimer: This is a PDF file of an unedited manuscript that has been accepted for publication. As a service to our customers we are providing this early version of the manuscript. The manuscript will undergo copyediting, typesetting, and review of the resulting proof before it is published in its final citable form. Please note that during the production process errors may be discovered which could affect the content, and all legal disclaimers that apply to the journal pertain. 


\section{Keywords}

Hypericum perforatum; Hypericum gentianoides; RAW 264.7 macrophages; Peritoneal macrophages; Inflammation; Lipopolysaccharide; Acylphloroglucinols; Pseudohypericin; Prostaglandin E2; Nitric oxide

\section{Introduction}

Hypericum perforatum (St. John's wort) has been among the most studied medicinal herbal plants, due to its popularity as an anti-depressant supplement (Linde and Knuppel, 2005). At the same time, increasing evidence also suggested that $H$. perforatum possess antiinflammatory and anti-viral activity, which could be potentially be used to alleviate conditions like inflammatory bowel disease, diarrhea, and respiratory infection (Birt et al., 2009; Hammer et al., 2007; Hu et al., 2006; Zdunic et al., 2009).

Besides H. perforatum, other species of the Hypericum genus are being studied to identify their constituents, as well as anti-inflammatory, anti-proliferation, and anti-microbial activities (Crockett et al., 2008; Henry et al., 2009; Kartnig et al., 1996). Among these species, a more lipophilic fraction of $H$. gentianoides methanol extract, rich in acylphloroglucinols, was found to have potent inhibitory effect on LPS-induced macrophage production of prostaglandin E2 (PGE2) (Hillwig et al., 2008).

Our previous studies have shown that $H$. perforatum ethanol extract inhibited LPS-induced PGE2 and nitric oxide (NO) production in RAW 264.7 macrophages, and attributed part of the activity of a highly active fraction of the extract to a group of four compounds including pseudohypericin, amentoflavone, quercetin and chlorogenic acid, shown and numbered in Figure 1 (Hammer et al., 2008; Hammer et al., 2007). But whether the 4 compounds could account for the activity of the complete extract, or if they can exert the same antiinflammatory potential in non-transformed primary macrophages remains unknown. On the other hand, the wide variety of Hypericum species provided us an opportunity to identify novel anti-inflammatory constituents. For instance, acylphloroglucinols in $H$. gentianoides were of particular interest. In the current study, we compared the anti-inflammatory potential of ethanol extracts made from various Hypericum species in the well established LPS-stimulated RAW 264.7 macrophages and used the chemical profiles of the more active species to identify novel agents not found in H. perforatum. In addition, we also tested key findings in primary mouse macrophages to further validate our results.

\section{Results}

\subsection{Cytotoxicity of Hypericum extracts, fractions, and pure constituents}

None of the extracts, fractions, or pure compounds reduced cell viability with treatments at the maximum concentrations that were used in bioactivity assays (data not shown). Therefore, the observed anti-inflammatory activity was not compromised by cytotoxicity.

\subsection{Inhibition of inflammatory mediators by different Hypericum extracts}

Extracts made from different Hypericum species and accessions were applied to RAW 264.7 macrophages at $10 \mu \mathrm{g} / \mathrm{mL}$. As shown in Table 1, almost all extracts significantly reduced LPS-induced PGE2 and NO production. Among all extracts tested, $H$. perforatum and $H$. gentianoides were the only two that inhibited both PGE2 and NO by more than $30 \%$ compared to the vehicle control. 


\subsection{LC-MS analysis of $\boldsymbol{H}$. perforatum extract}

Major identifiable compounds in a $H$. perforatum ethanol extract were quantified previously (Hammer et al., 2008). As Figure 2A shows the chromatogram of the extract used in the current study, which indicated a chemical profile similar to that previously reported (Hammer et al., 2008). The extract contained compounds 1-8; chlorogenic acid rutin, hyperoside, quercetin, amentoflavone, pseudohypericin, hyperforin, and hypericin.

\subsection{H. perforatum extract and its constituents inhibited LPS-induced inflammatory mediators}

Our prior study reported that a group of 4 compounds, comprised of pseudohypericin, amentoflavone, quercetin, and chlorogenic, acid (compounds 1-4), could account for part of the anti-inflammatory potential of $H$. perforatum extract (Hammer et al., 2010); In the current study, we applied DMSO vehicle control, H. perforatum extract, the 4 compounds or pseudohypericin (compound 1) alone at the concentrations they were found in the extract, to macrophages. The extract had stronger decreasing effect on PGE2 and NO than the 4 compounds. The 4 compounds inhibited TNF- $\alpha$ in the cell line and the primary cells, while the extract only decreased tumor necrosis factor (TNF)- $\alpha$ in peritoneal macrophages. Interleukin (IL)-1 $\beta$ was inhibited by the extract and 4 compounds to a similar degree. Pseudohypericin (compound 1) by itself was only able to mildly lower PGE2 and NO in RAW cells, as well as NO and TNF- $\alpha$ in the peritoneal macrophages. Quercetin positive control at $10 \mu \mathrm{M}$ significantly decreased all inflammatory mediators in both cell types.

\subsection{Fractionation of $\boldsymbol{H}$. perforatum extract}

The extract was subsequently fractionated into eleven fractions according to the peaks at different retention time using semi-preparative HPLC, as shown in Figure 2B.

\subsection{Fractions of $\boldsymbol{H}$. perforatum extract inhibited LPS-stimulated PGE2 and NO}

The eleven fractions made from $H$. perforatum extract were applied to RAW 264.7 macrophages at concentrations in proportion to their yield. As demonstrated in Table 3, all fractions significantly inhibited LPS-induced PGE2 and NO production. Fractions 3, 4, 6, 7 and 11 had the most potent inhibitory activity at relatively lower concentrations, all decreased PGE2 and NO by more than $40 \%$ compared to vehicle control. In order to see whether the fractions were lowering the inflammatory mediators in a dose-dependent manner, we treated the cells with the selected fractions 6,7 and 11 at $1 \mu \mathrm{g} / \mathrm{mL}, 5 \mu \mathrm{g} / \mathrm{mL}$, and $15 \mu \mathrm{g} / \mathrm{mL}$. Figure 3 indicates that the inhibition of both inflammatory mediators by these three fractions become stronger with higher dose. All three fractions inhibited NO at as low as $1 \mu \mathrm{g} / \mathrm{mL}$, with fraction 11 also able to significantly decrease PGE2 at this concentration. At $15 \mu \mathrm{g} / \mathrm{mL}$, fraction 11 was the most potent inhibitor of PGE2 and NO among the three, inhibiting PGE2 by $\sim 67 \%$ and NO by $\sim 85 \%$. Also in Figure 3, major known compounds identified in the fractions are listed below the corresponding fractions. Pseudohypericin (compound 1) was found in all three active fractions, while rutin and hyperoside were found in two of them.

\subsection{LC-MS analysis of $\boldsymbol{H}$. gentianoides extract}

Figure 4A shows the LS-MS chromatogram of $H$. gentianoides ethanol extract similar to Hillwig et al. reported for a methanol extract (Hillwig et al., 2008), which highlights a distinctive group of acylphloroglucinols including uliginosin A, saroaspidin A, and hyperbrasilol A (compounds 9-11). This extract also contains typical Hypericum constituents such as chlorogenic acid, quercetin (compounds 2 and 4) and isoquercetin. 


\subsection{Fractionation of $\boldsymbol{H}$. gentianoides extract}

The ethanol extract of $H$. gentianoides was fractionated into ten fractions based on semipreparative HPLC detection peaks at different retention time, as shown in Figure 4B.

\subsection{Fractions of $\boldsymbol{H}$. gentianoides extract inhibited LPS-stimulated PGE2 and NO}

All ten fractions made from $H$. gentianoides extract were applied to RAW 264.7 macrophages at concentrations proportional to their yield. As shown in Table 4, all but fractions 1 and 10 significantly inhibited LPS-induced PGE2 at the tested concentrations. Fractions 4, 6, 7, 8 and 9 had relatively stronger PGE2 inhibitory activity at concentrations less than $15 \mu \mathrm{g} / \mathrm{mL}$. With regards to $\mathrm{NO}$, fraction 4 was the only one that did not decrease NO production. Fractions 5, 6, 7, 8 and 9 all inhibited NO by $>50 \%$ at below $15 \mu \mathrm{g} / \mathrm{mL}$ concentrations. Fraction 8 was the apparent most potent fraction by inhibiting PGE2 by $93 \%$ and $\mathrm{NO}$ by $76 \%$. Fractions 5,8 and 9 at $1 \mu \mathrm{g} / \mathrm{mL}, 5 \mu \mathrm{g} / \mathrm{mL}$, and $15 \mu \mathrm{g} / \mathrm{mL}$ were applied to cells to establish dose-response relationship. Figure 5 illustrates that the fraction 8 was the only one among the three that could inhibit PGE2 at $1 \mu \mathrm{g} / \mathrm{mL}$ and NO at $5 \mu \mathrm{g} / \mathrm{mL}$. All three fractions inhibited PGE2 and NO in a dose-dependent fashion. Fractions 8 and 9 contained acylphloroglucinols, while fraction 5 contained chlorogenic acid and quercetin (compounds 2 and 4$)$.

\subsection{Uliginosin A in H. gentianoides extract and fractions inhibited LPS-induced inflammatory mediators}

The concentrations of uliginosin A (compound 9), the most abundant acylphloroglucinols in H. gentianoides, were quantified in the H. gentianoides extract, its fractions 5, 8 and 9 . RAW 264.7 macrophages were treated with the plant materials or pure uliginosin A (compound 9) at the concentration as it was in the extract and fractions. The resulting inhibition in PGE2 and NO are shown in Table 5. The abundance of uliginosin A (compound 9) in $48.5 \mu \mathrm{g} / \mathrm{mL} \mathrm{H}$. gentianoides extract was $0.6 \mu \mathrm{M}$. At concentrations used here, fractions 5,8 and 9 contained $0.04,2.0$, and $2.6 \mu \mathrm{M}$ uliginosin A (compound 9), respectively. PGE2 was inhibited by uliginosin A only at 2.0 and $2.6 \mu \mathrm{M}$, while NO, TNF- $\alpha$ and IL-1 $\beta$ were inhibited at $0.6 \mu \mathrm{M}$ as well. In general, uliginosin A (compound 9) accounted for a part of the inhibitory activity of the extract and fraction 8 . The trace amount of uliginosin A (compound 9) did not reduce the release of any inflammatory mediator or cytokine. At $2.6 \mu \mathrm{M}$, uliginosin A (compound 9) demonstrated comparable impact on inflammatory endpoints as fraction 9 .

\section{Discussion}

The anti-inflammatory potential and chemical profiles of various $H$. perforatum accessions extracted with different methods were previously evaluated (Hammer et al., 2007).

However, due to the existence of many other Hypericum species, which contain a variety of different compounds with different abundance, we expanded the activity screening to nine different extracts made from 2 accessions of $H$. perforatum and 7 other species including $H$. gentianoides, all harvested in 2008. The results shown in Table 1 indicate that all extracts except for Elixir were capable of inhibiting LPS-induced macrophage production of PGE2 and $\mathrm{NO}$ at $10 \mu \mathrm{g} / \mathrm{mL}$ concentration. Much to our surprise, Elixir was the least active in the current study, while being the most active in the study reported by Hammer et al. (Hammer et al., 2007). This could be attributed to year to year plant differences. Considering the overall inhibition on PGE2 and NO, H. perforatum and $H$. gentianoides extracts stood out as the most potent by decreasing both inflammatory mediators by more than $30 \%$; and thus became the focus of the subsequent studies. 
The anti-inflammatory potentials of $H$. perforatum ethanol extract has been studied extensively in our laboratory, with the 4 major active compounds (the 4 compounds) in its most active fraction identified and their impact on gene transcription reported (Hammer et al., 2008; Hammer et al., 2010). Because most dietary Hypericum supplements are made from extracts instead of fractions, whether the compounds identified, enriched in the active fraction, can also account for a portion of the extract activity is an important question to answer. Here we found that at the same concentrations as they were quantified in the extract, the 4 compounds accounted for a portion of the extract's PGE2 and NO inhibitory effect in RAW 264.7 macrophages (Table 2). In addition to PGE2 and NO, we measured TNF- $\alpha$ and IL-1 $\beta$ as well, and found that the 4 compounds inhibited both while the extract only inhibited IL-1 $\beta$, suggesting other components in the extract negate the inhibition of TNF- $\alpha$ by the 4 compounds. Since pseudohypericin (compound 1) was considered the pivotal compound among the 4 compounds, cells were treated with it alone (Hammer et al., 2008). Only mild but significant decrease in PGE2 and NO was found with pseudohypericin (compound 1) treatment, indicating its importance limited to certain inflammatory endpoints. RAW 264.7 macrophages are transformed macrophages that could behave differently compared to in vivo macrophages, making it necessary to replicate findings using primary peritoneal macrophages in order to interpret the results better (Johnston et al., 2010). The peritoneal macrophages generated similar results as compared to the RAW cells under the same treatments. The apparent differences between the two cell lines were that the extract inhibited TNF- $\alpha$ in the peritoneal macrophages, and that NO was inhibited by all treatments to a greater extent in these cells. Overall, the highly similar trends in by the treatments in the two cell lines made the anti-inflammatory potential of $H$. perforatum extracts and components more compelling.

After fractionation, the 4 compounds were no longer found together in any single fraction, despite the fact that most fractions were able to significantly inhibit LPS-induced PGE2 and $\mathrm{NO}$ production at the concentrations in proportion to their yield from the extract. Among all, fractions 6,7,11 were selected for chemical profiling using LC-MS and dose-response studies. As indicated in Figure 3, these fractions all contained pseudohypericin (compound 1), and other different known constituents, respectively. These three fractions also dosedependently inhibited PGE2 and NO production, showing significant impacts at doses as low as $5 \mu \mathrm{g} / \mathrm{mL}$. Our follow-up experiment in which sub-fractions of fraction 6 were applied to LPS-stimulated RAW 264.7 cells showed that those sub-fractions that had inhibitory activity contained higher amount of compound 1 (data not shown). Together, we expanded the previously identified importance of pseudohypericin (compound 1) from the antiinflammatory potential of one particular sub-fraction to $H$. perforatum ethanol extract and fractions (Hammer et al., 2008).

Acylphloroglucinols have been suggested by Hillwig et al. as active components in the methanol extract of $H$. gentianoides (Hillwig et al., 2008). In the current study, we found that the lipophilic fractions of $H$. gentianoides ethanol extract, which were enriched with these acylphloroglucinols, had potent inhibitory activity on LPS-stimulated PGE2 and NO in macrophages. Fractions 8 inhibited as much as $90 \%$ of the LPS-induced PGE2 production. Not all Hypericum species contain significant amount of phloroglucinols, which have been found in $H$. densiflorum, H. chinence, H. balearicum, and $H$. empetrifolium, etc. (Crockett et al., 2008; Henry et al., 2009; Tanaka et al., 2009). However, the existence of this group of relatively less studied anti-inflammatory constituents in certain Hypericum species, especially $H$. gentianoides as shown in the current study, could account for a part of the observed differences among the species in their anti-inflammatory potentials. To pursue this hypothesis, we quantified the amount of the most abundant acylphloroglucinol in $H$. gentianoides, uliginosin A (compound 9) in the extract and three active fractions, and used pure uliginosin A (compound 9) at the same concentrations as it was in the extract and 
fraction to treat RAW 264.7 macrophages. Uliginosin A (compound 9) at the concentration as in the extract inhibited NO, TNF- $\alpha$, and IL-1 $\beta$ more moderately compared to the extract, but did not significantly reduce LPS-induced PGE2. Uliginosin A (compound 9) in fraction 5 did not account for its anti-inflammatory impact, while the activity of fractions 8 and 9 could be attributed to their relatively abundant uliginosin A (compound 9). It is intriguing that lipophilic fractions of $H$. gentianoides had strong anti-inflammatory potential that could be largely attributed to uliginosin A (compound 9) enriched in these fractions, as this is different from $H$. perforatum extract and fractions.

The anti-inflammatory activity of acylphloroglucinols, especially uliginosin A (compound 9) is not well characterized (Crockett et al., 2008). The inhibitory effect of uliginosin A (compound 9) on PGE2 synthesis observed here might be due to inhibition of microsomal PGE synthase-1 as suggested by Koeberle et al (Koeberle et al., 2009), since a reduction in cyclooxygenase-2 (COX-2) protein expression were not observed (data not shown). As uliginosin A (compound 9) inhibited PGE2, NO, TNF- $\alpha$, and IL-1 $\beta$, it is reasonable to speculate that an upstream inflammation regulator could be its molecular target.

In order to determine the anti-inflammatory activity of uliginosin A (compound 9) in $H$. gentianoides, in vivo studies such as Rossi et al. reported are necessary (Rossi et al., 2009). In addition, bioavailability of acylphloroglucinols needs to be characterized to validate the potential for in vivo efficacy of these compounds. Although we again confirmed the importance of the 4 compounds to the anti-inflammatory potential of $H$. perforatum extract and fractions, the relatively poor bioavailability of these compounds make it challenging to predict bioactivity in in vivo models. For example, peak plasma pseudohypericin (compound 1) was $16.3 \mathrm{nM}$ in humans after consuming $612 \mathrm{mg} H$. perforatum aqueous ethanol extract that contained $0.2 \%$ total hypericins and $9 \%$ total flavonoids (Schulz et al., 2005). The same study also found the maximum plasma quercetin concentration of $0.16 \mu \mathrm{M}$. As all the concentrations shown above are lower than those used in the current study, further studies on the in vivo anti-inflammatory activity of $H$. perforatum extract and the 4 compounds in it are required.

\section{Conclusion}

A group of 4 components and uliginosin A respectively contributed to the anti-inflammatory potential of $H$. perforatum and $H$. gentianoides ethanol extracts and active fractions in murine macrophages. Further studies could focus on the molecular targets of these different active constituents as well as their in vivo efficacy.

\section{Experimental}

\subsection{Plant Materials}

Flower stems of $H$. densiflorum (Accession Ames 27061), H. beanii (Ames 27441), $H$. perforatum 'Medizinal'(Elixir ${ }^{\mathrm{TM}}$ ) (Ames 27452), H. balearicum (Ames 27471), H. bellum (Ames 27472), H. forrestii (Ames 27479), H. patulum (Ames 27489), H. gentianoides (Ames 28015), and H. perforatum (PI 325351), were harvested between June $17^{\text {th }}$ and July 29 ${ }^{\text {th }}, 2008$ from the North Central Regional Plant Introduction Station (NCRPIS) (Ames, IA) of the U.S. Department of Agriculture, Agricultural Research Service (USDA/ARS). The harvested material was dried and ground before being stored at $-20{ }^{\circ} \mathrm{C}$ as previously described (Schmitt et al., 2006a). Additional information about these accessions is available from the Germplasm Resources Information Network (GRIN) database at: http://www.ars-grin.gov/npgs/acc/acc_queries.html. 


\subsection{Extraction and Fractionation of Hypericum plant material}

Six grams of dried and ground Hypericum material was extracted for $6 \mathrm{~h}$ via Soxhlet with $500 \mathrm{~mL} 95 \%$ ethanol. The extracted product was then filtered before being dried by rotary evaporation at $40{ }^{\circ} \mathrm{C}$, followed by lyophilization. The resulting extract was dissolved in DMSO to stock concentrations and stored protected from light exposure at $-20^{\circ} \mathrm{C}$.

Approximately $0.5 \mathrm{ml}$ of $100 \mathrm{mg} / \mathrm{ml}$ Hypericum extract, dissolved in $60 \%$ ethanol, was loaded onto an YMC-pack ODS-AM 250×10 mm column (AM12S05-2510WT, YMC, Allentown, PA). The HPLC system used was a Beckman-Coulter System Gold with a 126 solvent module, a 168 detector, and an Isco Retriever 500 Fraction Collector. Solvents were A: endotoxin-free water containing $0.1 \%$ acetic acid and B: pure acetonitrile. The gradient used was from $10 \%$ to $100 \%$ B for 50 min followed by 2 minutes of $100 \%$ B and reequilibration at $10 \%$ B for 5 minutes. $2 \mathrm{ml}$ fractions were collected and later pooled based on HPLC peaks at $330 \mathrm{~nm}$. Depending on the species, ten to twelve fractions were obtained, which were concentrated by lyophilization and dissolved in DMSO for storage. All extracts and fractions used here have been screened for endotoxin and no detectable level was found (Huang et al., 2009).

\subsection{Chemicals}

Pseudohypericin (compound 1) at $\geq 98 \%$ purity, according to the manufacturer, was purchased from Axxora (San Diego, CA). Quercetin, amentoflavone and chlorogenic acid (compounds 1-3) at $\geq 98 \%, \geq 99 \%$ and $\geq 95 \%$ purity, respectively, were acquired from Sigma Aldrich (St. Louis, MO). These chemicals were dissolved in DMSO to $100 \mu \mathrm{M}$ stock concentration, stored at $-20^{\circ} \mathrm{C}$ and protected from light exposure upon arrival. Uliginosin $\mathrm{A}$ (compound 9) was synthesized and provided by Dr. George Kraus (unpublished).

\subsection{Chemical analysis of plant materials}

The analysis of extracts and fractions, and quantification of compounds were perform on Agilent Technologies' Ion Trap 1100 coupled to a UV absorption detector LC-ESI-MS-UV. A Zorbax Eclipse Plus C8 $3.5 \mu \mathrm{m}, 2.1 \times 150 \mathrm{~mm}$ column (Agilent, Santa Clara CA) was used for separation. For the mobile phase, an acetonitrile/methanol 9:1 v/v (solvent B) and 10 $\mathrm{mM}$ ammonium acetate (solvent $\mathrm{A}$ ) gradient was used. The gradient was increased from $85 \% \mathrm{~A} / 15 \%$ B over a $10 \mathrm{~min}$ time period to $80 \% \mathrm{~A} / 20 \% \mathrm{~B}$, then to $100 \% \mathrm{~B}$ over a $25 \mathrm{~min}$ time period, and held at $100 \% \mathrm{~B}$ for $5 \mathrm{~min}$. The flow rate was $0.17 \mathrm{~mL} / \mathrm{min}$ and chromatography was conducted at $40{ }^{\circ} \mathrm{C}$ (Hillwig et al., 2008). All solvents were HPLC grade (Sigma, St. Louis, MO).

\subsection{Cell Culture and Treatment with Plant Materials}

RAW 264.7 mouse macrophages (American Type Culture Collection, Manassas, VA) were maintained in high-glucose Dulbecco's Modified Eagle's medium (DMEM) with supplementations of $100 \mathrm{IU} / \mathrm{mL}$ penicillin/streptomycin, $10 \%$ fetal bovine serum and $1 \%$ sodium bicarbonate (all from Invitrogen, Carlsbad, CA) as described before under 5\% carbon dioxide at $37{ }^{\circ} \mathrm{C}$ (Hammer et al., 2007). Mouse peritoneal macrophages were collected by flushing the peritoneal cavity of euthanized C57/B6 mice with 6-8 $\mathrm{mL}$ of sterile phosphate saline buffer (PBS) (Invitrogen) (Johnston et al., 2010). The lavage fluid was centrifuged at $5000 \times \mathrm{g}$. Cell pellets were suspended with DMEM medium supplemented with $100 \mathrm{IU} / \mathrm{mL}$ penicillin/streptomycin, $0.25 \mu \mathrm{g} / \mathrm{mL}$ amphotericin, and $10 \%$ fetal bovine before being plated to 24 well plates at $5 \times 10^{5}$ cells per well or 48 well plates at $2 \times 10^{5}$ cells per well. Treatments of extract and pure compounds were applied to cells for PGE2, NO, and cytotoxicity assays as reported in prior studies (Hammer et al., 2010; Huang et al., 2009). Because light-activation is required for the inhibitory properties of naphthodianthrone 
compounds in Hypericum species on LPS-induced PGE2, experiments were conducted in the dark with a $30 \mathrm{~min}$ standard fluorescent lamp light-activation at right after the treatments were applied to the cells (Schmitt et al., 2006a). All cell culture experiments were done in triplicates in one experiment, using cells from different culture flasks for each plate.

\subsection{Cytotoxicity Measurement}

The Hypericum extracts, fractions and pure compounds that were screened for antiinflammatory potential were also tested for toxicity against RAW 264.7 macrophages and peritoneal macrophages using a protocol modified from our prior study (Huang et al., 2009). In brief, RAW 264.7 macrophages and primary peritoneal macrophages were plated in 48well plates at $5 \times 10^{4}$ cells per well and treated with Hypericum extracts at $30 \mu \mathrm{g} / \mathrm{mL}$ and the fractions at the highest concentrations used in this study for $24 \mathrm{~h}$ with a $30 \mathrm{~min}$ lightactivation. The resulting cell viability was measured using Celltiter96 Aqueous One Solution Cell Proliferation Assay (Promega, Madison, WI).

\subsection{Measurement of Prostaglandin E2, Nitric Oxide and Cytokines}

Cell culture supernatant was collected after $8 \mathrm{~h}$ treatment for PGE2 assay, or after $24 \mathrm{~h}$ treatment for NO and cytokine measurements. PGE2 was measured using a Biotrek PGE2 enzyme immune assay kit (GE Healthcare, Piscataway, NJ) and NO levels were assessed with Griess reagent (Promega, Madison, WI) as described (Schmitt et al., 2006b). Concentrations of IL- $1 \beta$ and TNF- $\alpha$ were measured using enzyme-linked immunosorbent assay (ELISA) kits (BD Biosciences, Franklin Lakes, NJ) according to the manufacturer's instructions.

\subsection{Statistical Analysis}

Cell viability, PGE2, NO, and cytokine assay results were analyzed using randomized complete block ANOVA with each of the three cell culture plates as a fixed block. PGE2 and cytokine levels were log-transformed before the analysis in order to normalize the data. In the figures, all treatments were compared to the media + DMSO vehicle control with LPS stimulation, and reported as percentage of the vehicle control in mean \pm SEM for each treatment. PGE2, NO, TNF- $\alpha$, and IL-1 $\beta$ levels are presented in data tables in concentrations. PGE2 and NO induction by LPS were similar across experiments. Quercetin positive control at $10 \mu \mathrm{M}$ inhibited LPS-stimulated PGE2 by $20-40 \%$ and NO by $30-45 \%$ in individual assays. The $H$. perforatum extract at $30 \mu \mathrm{g} / \mathrm{mL}$ consistently inhibited LPSstimulated PGE2 and NO by $\sim 60 \%$ and $\sim 40 \%$ respectively in different experiments, although results are not shown in every figure. Multiple comparisons between individual treatments and the vehicle control were made using pair wise student $t$ test (all using SAS 9.0 SAS Institute, Cary, NC).

\section{Acknowledgments}

We thank members of the Iowa Center for Research on Botanical Dietary Supplements. Especial thanks to the North Central Regional Plant Introduction Station (NCRPIS) (Ames, IA) of the U.S. Department of Agriculture, Agricultural Research Service (USDA/ARS) for providing plant material and to Dr. Ann Perera, manager of the W. M. Keck Metabolomics Facility, at Iowa State University for providing the analytical instrumentation. This work is sponsored by P50 AT004155-06 from NCAAM/ODS, NIH.

\section{References}

Birt DF, Widrlechner MP, Hammer KD, Hillwig ML, Wei J, Kraus GA, Murphy PA, McCoy J, Wurtele ES, Neighbors JD, Wiemer DF, Maury WJ, Price JP. Hypericum in infection: Identification of anti-viral and anti-inflammatory constituents. Pharm Biol. 2009; 47:774-782. [PubMed: 19907671] 
Crockett SL, Wenzig E-M, Kunert O, Bauer R. Anti-inflammatory phloroglucinol derivatives from Hypericum empetrifolium. Phytochemistry Letters. 2008; 1:37-43. [PubMed: 21151761]

Hammer KD, Hillwig ML, Neighbors JD, Sim YJ, Kohut ML, Wiemer DF, Wurtele ES, Birt DF. Pseudohypericin is necessary for the light-activated inhibition of prostaglandin E2 pathways by a 4 component system mimicking an Hypericum perforatum fraction. Phytochemistry. 2008; 69:23542362. [PubMed: 18707743]

Hammer KD, Hillwig ML, Solco AK, Dixon PM, Delate K, Murphy PA, Wurtele ES, Birt DF. Inhibition of prostaglandin $\mathrm{E}(2)$ production by anti-inflammatory hypericum perforatum extracts and constituents in RAW264.7 Mouse Macrophage Cells. J Agric Food Chem. 2007; 55:73237331. [PubMed: 17696442]

Hammer KD, Yum MY, Dixon PM, Birt DF. Identification of JAK-STAT pathways as important for the anti-inflammatory activity of a Hypericum perforatum fraction and bioactive constituents in RAW 264.7 mouse macrophages. Phytochemistry. 2010; 71:716-725. [PubMed: 20303133]

Henry GE, Campbell MS, Zelinsky AA, Liu Y, Bowen-Forbes CS, Li L, Nair MG, Rowley DC, Seeram NP. Bioactive acylphloroglucinols from Hypericum densiflorum. Phytother Res. 2009

Hillwig ML, Hammer KD, Birt DF, Wurtele ES. Characterizing the metabolic fingerprint and antiinflammatory activity of Hypericum gentianoides. J Agric Food Chem. 2008; 56:4359-4366. [PubMed: 18512936]

Hu ZP, Yang XX, Chan SY, Xu AL, Duan W, Zhu YZ, Sheu FS, Boelsterli UA, Chan E, Zhang Q, Wang JC, Ee PL, Koh HL, Huang M, Zhou SF. St. John's wort attenuates irinotecan-induced diarrhea via down-regulation of intestinal pro-inflammatory cytokines and inhibition of intestinal epithelial apoptosis. Toxicol Appl Pharmacol. 2006; 216:225-237. [PubMed: 17015070]

Huang N, Hauck C, Yum MY, Rizshsky L, Widrlechner MP, McCoy JA, Murphy PA, Dixon PM, Nikolau BJ, Birt DF. Rosmarinic acid in Prunella vulgaris ethanol extract inhibits lipopolysaccharide-induced prostaglandin E2 and nitric oxide in RAW 264.7 mouse macrophages. J Agric Food Chem. 2009; 57:10579-10589. [PubMed: 19919113]

Johnston MJ, Wang A, Catarino ME, Ball L, Phan VC, MacDonald JA, McKay DM. Extracts of the rat tapeworm, Hymenolepis diminuta, suppress macrophage activation in vitro and alleviate chemically induced colitis in mice. Infect Immun. 2010; 78:1364-1375. [PubMed: 20028812]

Kartnig T, Gobel I, Heydel B. Production of hypericin, pseudohypericin and flavonoids in cell cultures of various Hypericum species and their chemotypes. Planta Med. 1996; 62:51-53. [PubMed: 8720388]

Koeberle A, Pollastro F, Northoff H, Werz O. Myrtucommulone, a natural acylphloroglucinol, inhibits microsomal prostaglandin E(2) synthase-1. Br J Pharmacol. 2009; 156:952-961. [PubMed: 19298395]

Linde K, Knuppel L. Large-scale observational studies of hypericum extracts in patients with depressive disorders--a systematic review. Phytomedicine. 2005; 12:148-157. [PubMed: 15693723]

Rossi A, Di Paola R, Mazzon E, Genovese T, Caminiti R, Bramanti P, Pergola C, Koeberle A, Werz O, Sautebin L, Cuzzocrea S. Myrtucommulone from Myrtus communis exhibits potent antiinflammatory effectiveness in vivo. J Pharmacol Exp Ther. 2009; 329:76-86. [PubMed: 19056932]

Schmitt LA, Liu Y, Murphy PA, Birt DF. Evaluation of the light-sensitive cytotoxicity of Hypericum perforatum extracts, fractions, and pure compounds. J Agric Food Chem. 2006a; 54:2881-2890. [PubMed: 16608204]

Schmitt LA, Liu Y, Murphy PA, Petrich JW, Dixon PM, Birt DF. Reduction in hypericin-induced phototoxicity by Hypericum perforatum extracts and pure compounds. J Photochem Photobiol B. 2006b; 85:118-130. [PubMed: 16859921]

Schulz HU, Schurer M, Bassler D, Weiser D. Investigation of the bioavailability of hypericin, pseudohypericin, hyperforin and the flavonoids quercetin and isorhamnetin following single and multiple oral dosing of a hypericum extract containing tablet. Arzneimittelforschung. 2005; 55:1522. [PubMed: 15727160] 
Tanaka N, Kashiwada Y, Kim SY, Hashida W, Sekiya M, Ikeshiro Y, Takaishi Y. Acylphloroglucinol, biyouyanagiol, biyouyanagin B, and related spiro-lactones from Hypericum chinense. J Nat Prod. 2009; 72:1447-1452. [PubMed: 19606850]

Zdunic G, Godevac D, Milenkovic M, Vucicevic D, Savikin K, Menkovic N, Petrovic S. Evaluation of Hypericum perforatum oil extracts for an antiinflammatory and gastroprotective activity in rats.

Phytother Res. 2009 


\section{Research Highlights}

- H. perforatum and H. gentianoides ethanol extracts inhibited inflammatory mediators.

- The 4 compounds contributed to H. perforatum's anti-inflammatory potential.

- Lipophilic fractions of $H$. gentianoides drastically inhibited inflammatory mediators.

- Uliginosin A and other acylphloroglucinols were active compounds in $H$. gentianoides. 


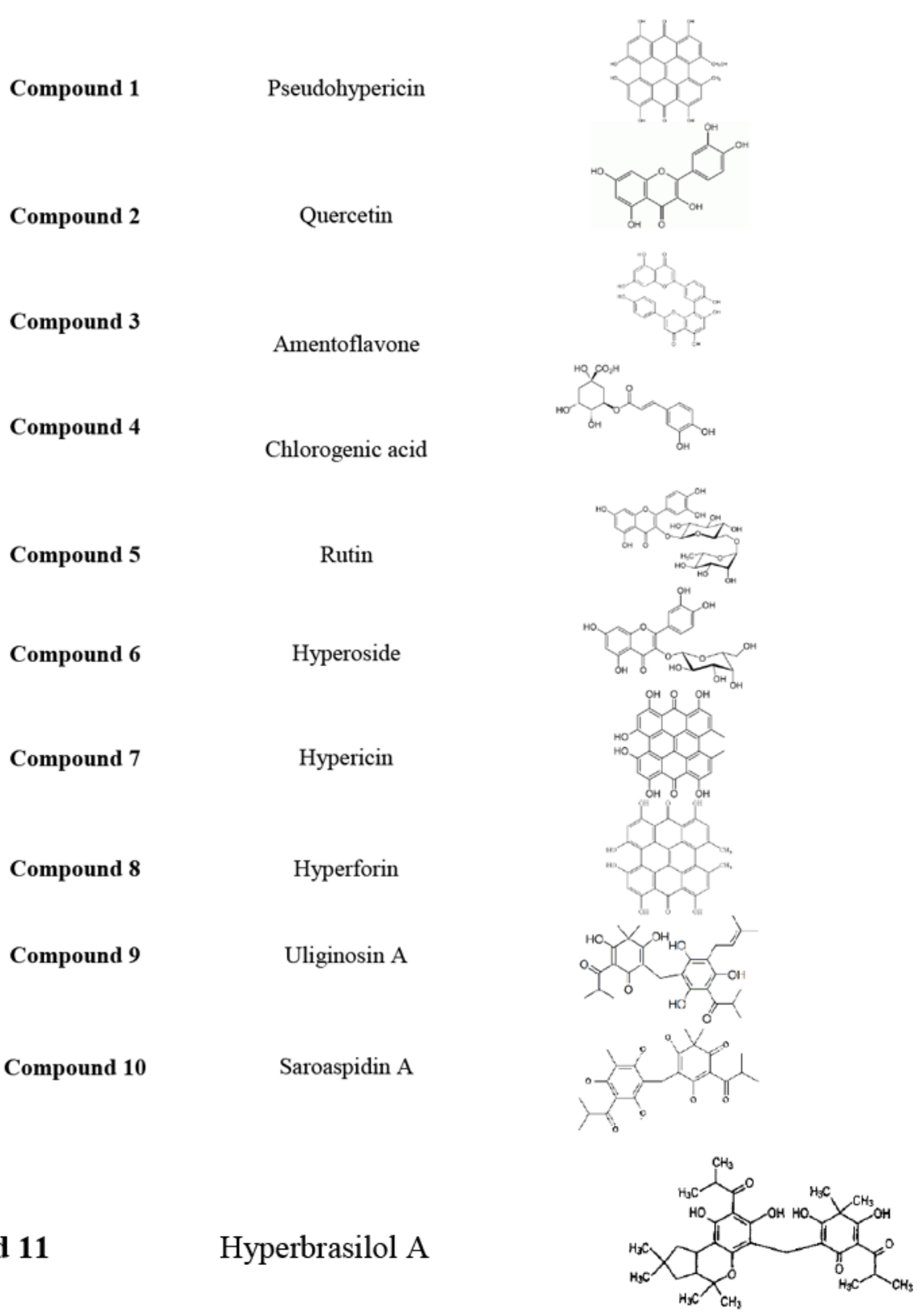

\section{Compound 11}

Hyperbrasilol A

Figure 1. LC-MS analysis of and fractionation of $\boldsymbol{H}$. perforatum extract Ethanol extract of $H$. perforatum was analyzed using LC-MS (A). Detected peaks are shown here with their corresponding constituents. The extract was further fractionated into 11 fractions using semi-preparative HPLC according to elusion time (B).

Phytochemistry. Author manuscript; available in PMC 2012 November 1. 
A

LC-MS analysis of Hypericum perforatum extract

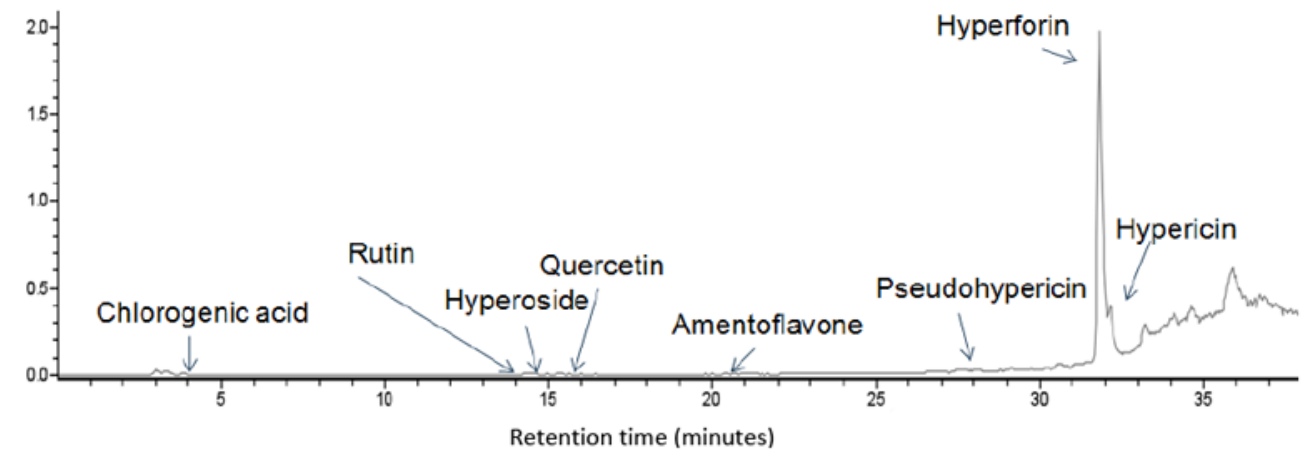

B

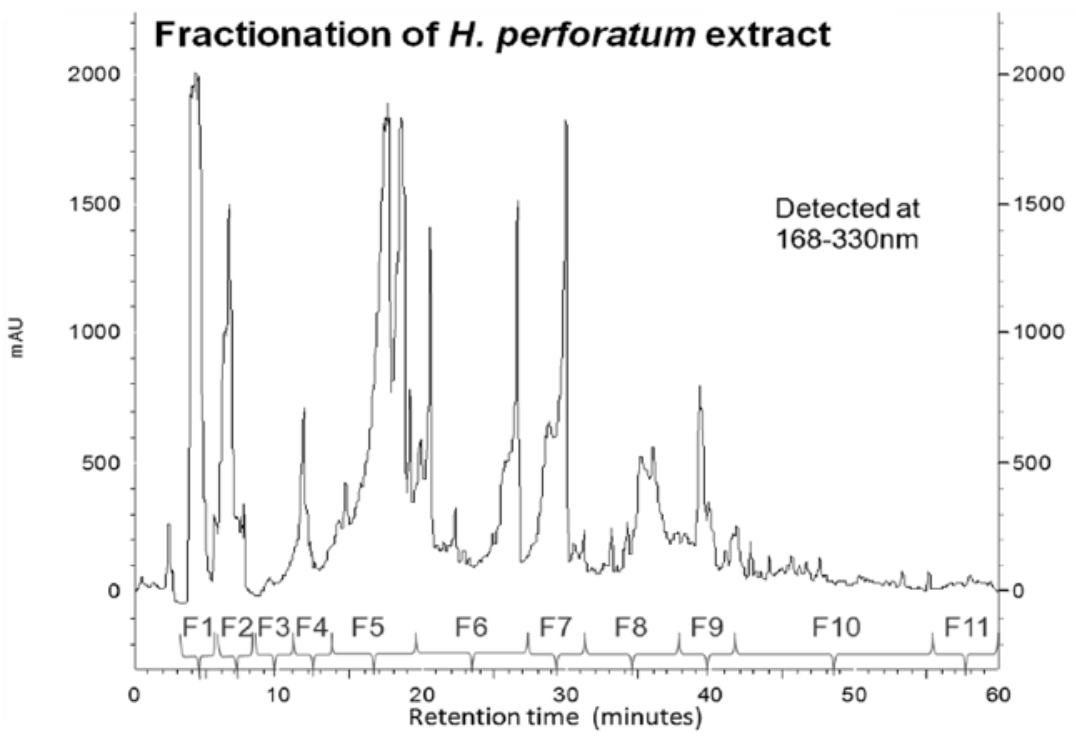

Figure 2. Inhibition of PGE2 and NO by active fractions from $\boldsymbol{H}$. perforatum extract and identification of their known constituents

Active fractions of $H$. perforatum extract at a series of three concentrations of 1, 5, and 15 $\mu \mathrm{g} / \mathrm{mL}$ were applied to RAW 264.7 macrophages with $1 \mu \mathrm{g} / \mathrm{mL}$ LPS stimulation. Quercetin was used as positive control at $10 \mu \mathrm{M}$. Production of PGE2 and NO after $8 \mathrm{~h}$ and $24 \mathrm{~h}$ treatment respectively are shown as percentage of DMSO vehicle control (Mean \pm SEM, $\mathrm{n}=3$ ). The $100 \%$ levels of PGE2 and NO were $5.5 \pm 0.5 \mathrm{ng} / \mathrm{mL}$ and $16.5 \pm 0.2 \mu \mathrm{M}$, respectively $*$ and $* *$ indicate significant $(\mathrm{p}<0.05$ and $\mathrm{p}<0.01)$ difference compared to media + DMSO vehicle control. Known compounds found in these extracts using LC-MS are shown under individual fractions. 


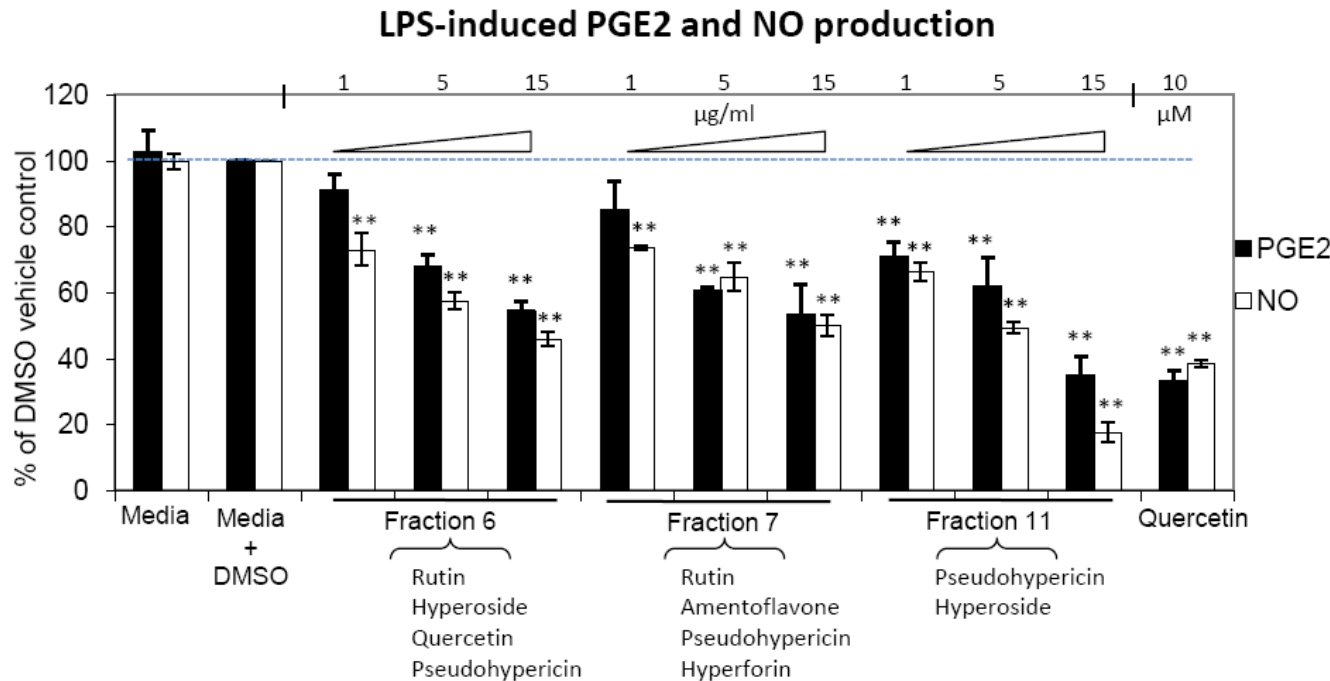

Figure 3. LC-MS analysis of and fractionation of $\boldsymbol{H}$. gentianoides extract Ethanol extract of $H$. gentianoides was analyzed using LC-MS (A). Detected peaks are shown here with their corresponding constituents. The extract was further fractionated into 10 fractions using semi-preparative HPLC according to elusion time (B). 
A

\section{LC-MS analysis of Hypericum gentianoides extract}

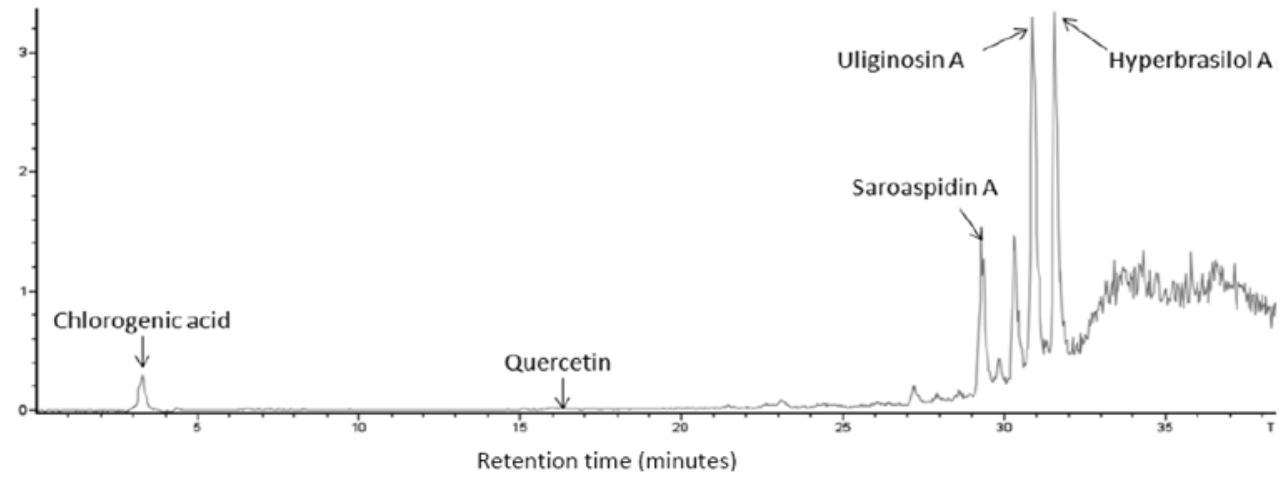

B

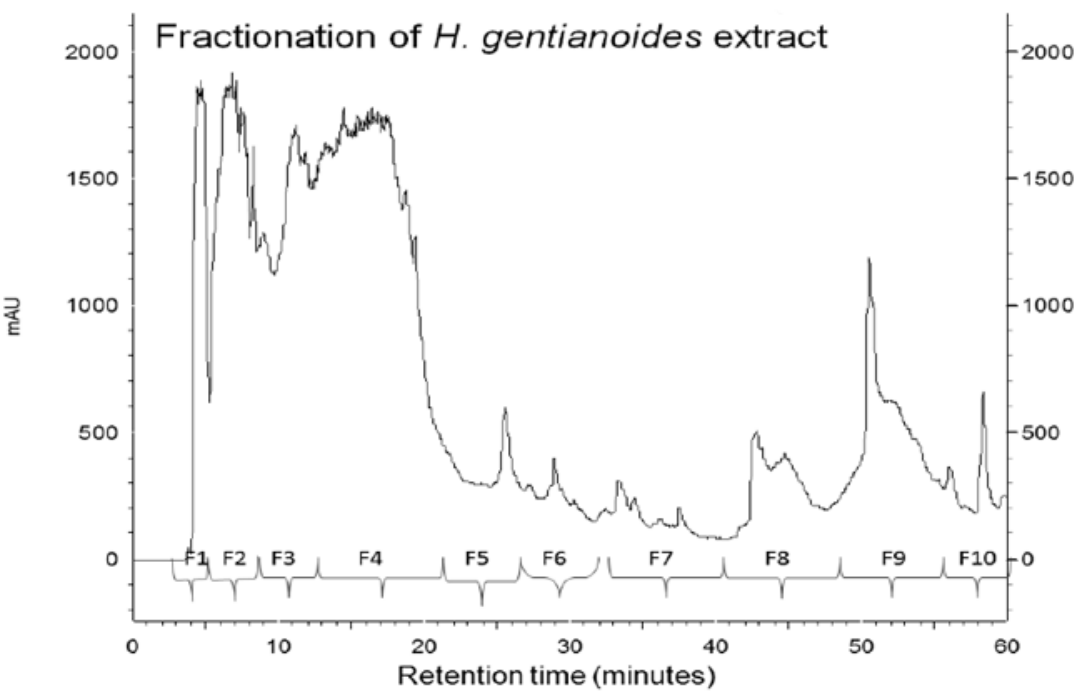

Figure 4. Inhibition of PGE2 and NO by active fractions from $\mathrm{H}$. gentianoides extract and identification of their known constituents

Active fractions of $H$. gentainoides extract at a series of three concentrations of 1,5 , and 15 $\mu \mathrm{g} / \mathrm{mL}$ were applied to RAW 264.7 macrophages with $1 \mu \mathrm{g} / \mathrm{mL}$ LPS stimulation. Quercetin was used as positive control at $10 \mu \mathrm{M}$. Production of PGE2 and NO after $8 \mathrm{~h}$ and $24 \mathrm{~h}$ treatment respectively are shown as percentage of DMSO vehicle control (Mean \pm SEM, $\mathrm{n}=3$ ). The $100 \%$ levels of PGE2 and NO were $5.5 \pm 0.5 \mathrm{ng} / \mathrm{mL}$ and $16.5 \pm 0.2 \mu \mathrm{M}$, respectively * and $* *$ indicate significant $(\mathrm{p}<0.05$ and $\mathrm{p}<0.01)$ difference compared to media + DMSO vehicle control. Known compounds found in these extracts using LC-MS are shown under individual fractions. 


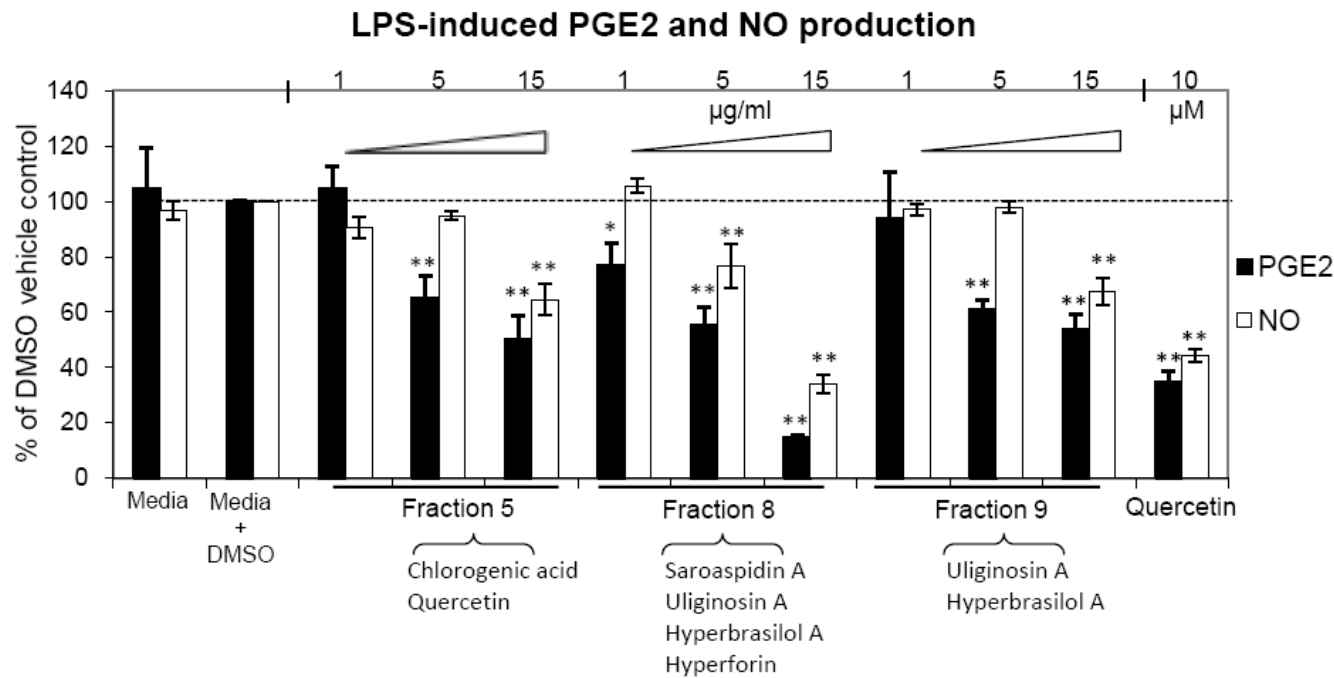

Fig. 5. Inhibition of PGE2 and NO by active fractions from H. gentianoides extract and identification of their known constituents

Active fractions of $\mathrm{H}$. gentainoides extract at a series of three concentrations of 1,5 , and 15 $\mu \mathrm{g} / \mathrm{mL}$ were applied to RAW 264.7 macrophages with $1 \mu \mathrm{g} / \mathrm{mL}$ LPS stimulation. Quercetin (2) was used as positive control at $10 \mu \mathrm{M}$. Production of PGE2 and NO after $8 \mathrm{~h}$ and $24 \mathrm{~h}$ treatment, respectively, are shown as percentage of DMSO vehicle control (mean \pm SEM, $n$ =3). The $100 \%$ levels of PGE2 and NO were $5.5 \pm 0.5 \mathrm{ng} / \mathrm{mL}$ and $16.5 \pm 0.2 \mu \mathrm{M}$, respectively. $*$ and $* *$ indicate significant $(\mathrm{p}<0.05$ and $\mathrm{p}<0.01)$ difference compared to media + DMSO vehicle control. Known compounds found in these extracts using LC-MS are shown under individual fractions. 


\section{Table 1}

LPS-stimulated RAW 264.7 mouse macrophages production of PGE2 and NO under the treatment of extracts of different Hypericum species and accessions.

\begin{tabular}{|c|c|c|c|}
\hline \multicolumn{2}{|r|}{ Treatments } & PGE2 (ng/mL) & NO $(\mu \mathrm{M})$ \\
\hline \multicolumn{2}{|r|}{ Media + DMSO } & $4.7 \pm 0.3$ & $24.8 \pm 1.9$ \\
\hline \multirow{10}{*}{$\begin{array}{l}\text { Extracts at } \\
10 \mu \mathrm{g} / \mathrm{mL}\end{array}$} & H. densiflorum & $3.7 \pm 0.3 *$ & $18.5 \pm 1.0^{* *}$ \\
\hline & H. beanii & $3.0 \pm 0.2 * *$ & $18.3 \pm 1.0^{* *}$ \\
\hline & H. perforatum Elixir & $3.8 \pm 0.3 *$ & $24.0 \pm 1.3$ \\
\hline & H. balearicum & $3.7 \pm 0.2 * *$ & $22.4 \pm 0.6 *$ \\
\hline & H. bellum & $3.5 \pm 0.1 * *$ & $18.4 \pm 1.0^{* *}$ \\
\hline & H. forrestii & $3.7 \pm 0.1 * *$ & $19.2 \pm 0.4 *$ \\
\hline & H. patulum & $2.5 \pm 0.2 * *$ & $21.0 \pm 0.8 *$ \\
\hline & H. gentianoides & $2.9 \pm 0.3 * *$ & $16.8 \pm 1.1^{* *}$ \\
\hline & H. perforatum & $2.6 \pm 0.1 * *$ & $16.2 \pm 1.3^{* *}$ \\
\hline & lercetin at $10 \mu \mathrm{M}$ & $1.1 \pm 0.1 * *$ & $11.8 \pm 0.7^{* *}$ \\
\hline \multicolumn{4}{|c|}{$\begin{array}{l}\text { Cells were treated with } 10 \mu \mathrm{g} / \mathrm{mL} \text { ethanol extracts made from different species and accessions of } \\
\text { Hypericum with } 1 \mu \mathrm{g} / \mathrm{mL} \text { LPS stimulation. The production of inflammatory mediators PGE2 and NO } \\
\text { after } 8 \mathrm{~h} \text { and } 24 \mathrm{~h} \text { treatment is shown (Mean } \pm \mathrm{SEM}, \mathrm{n}=3 \text { ). * and } * * \text { indicate significant }(\mathrm{p}<0.05 \text { and } \\
\mathrm{p}<0.01 \text { ) difference compared to media+DMSO vehicle control. }\end{array}$} \\
\hline
\end{tabular}


Table 2

LPS-stimulated inflammatory mediator and cytokine release by mouse macrophages treated with $H$. perforatum extract and its compounds.

\begin{tabular}{|c|c|c|c|c|c|c|}
\hline & \multirow[t]{2}{*}{ Treatments } & \multirow[t]{2}{*}{ Concentration } & PGE2 & NO & TNF- $\alpha$ & IL-1ק \\
\hline & & & \multicolumn{4}{|c|}{ Levels in supernatant (mean $\pm S E M$ ) } \\
\hline \multirow{5}{*}{ 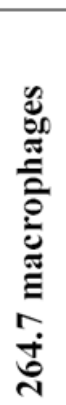 } & & & $\mathbf{n g} / \mathbf{m L}$ & $\mu \mathrm{M}$ & $\mathbf{n g} / \mathbf{m L}$ & $\mathrm{pg} / \mathrm{mL}$ \\
\hline & Media+DMSO & & $\mathbf{0 . 0 4} \pm 0.0$ & $\mathbf{0 . 0 1} \pm 0.2$ & $0.23 \pm 0.3$ & $83.2 \pm 10$ \\
\hline & Media+DMSO+LPS & & $4.5 \pm 0.6^{\mathrm{a}}$ & $24.1 \pm 1.0^{\mathrm{a}}$ & $9.0 \pm 0.3^{\mathrm{a}}$ & $488 \pm 12^{\mathrm{a}}$ \\
\hline & H. perforatum extract & $30 \mu \mathrm{g} / \mathrm{mL}$ & $1.9 \pm 0.4^{\mathrm{c}}$ & $14.6 \pm 0.5^{c}$ & $8.6 \pm 0.1$ & $368 \pm 7^{\mathrm{c}}$ \\
\hline & 4 compounds & $\left\{\begin{array}{l}1: 0.08 \mu \mathrm{M} \\
2: 0.38 \mu \mathrm{M} \\
3: 0.03 \mu \mathrm{M} \\
4: 0.58 \mu \mathrm{M}\end{array}\right.$ & $3.2 \pm 0.3^{\mathrm{b}}$ & $18.1 \pm 0.2^{\mathrm{c}}$ & $6.3 \pm 0.2^{\mathrm{c}}$ & $375 \pm 9^{c}$ \\
\hline \multirow{2}{*}{$\underset{⿱ 亠 乂}{\longleftarrow}$} & Pseudohypericin & $0.08 \mu \mathrm{M}$ & $3.5 \pm 0.2^{b}$ & $21.6 \pm 0.6^{b}$ & $8.6 \pm 0.2$ & $470 \pm 28$ \\
\hline & Quercetin & $10 \mu \mathrm{M}$ & $1.4 \pm 0.2^{\mathrm{c}}$ & $9.5 \pm 0.1^{c}$ & $3.4 \pm 0.5^{\mathrm{c}}$ & $374 \pm 25^{c}$ \\
\hline \multirow{7}{*}{ 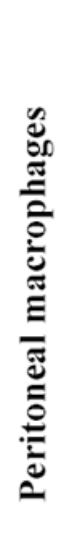 } & & & $\mathbf{n g} / \mathbf{m L}$ & $\mu \mathrm{M}$ & $\mathrm{pg} / \mathrm{mL}$ & $\mathrm{pg} / \mathrm{mL}$ \\
\hline & Media+DMSO & & $0.18 \pm 0.0$ & $0.62 \pm 0.1$ & $31.1 \pm 2.1$ & $13.0 \pm 1.3$ \\
\hline & Media+DMSO+LPS & & $1.12 \pm 0.1^{\mathrm{a}}$ & $3.73 \pm 0.4^{\mathrm{a}}$ & $91.6 \pm 4.1^{\mathrm{a}}$ & $161 \pm 1.3^{\mathrm{a}}$ \\
\hline & H. perforatum extract & $30 \mu \mathrm{g} / \mathrm{mL}$ & $0.69 \pm 0.1^{\mathrm{c}}$ & $1.54 \pm 0.1^{c}$ & $67.5 \pm 1.7^{\mathrm{c}}$ & $119.5 \pm 17^{b}$ \\
\hline & 4 compounds & $\left\{\begin{array}{l}1: 0.08 \mu \mathrm{M} \\
2: 0.38 \mu \mathrm{M} \\
3: 0.03 \mu \mathrm{M} \\
4: 0.58 \mu \mathrm{M}\end{array}\right.$ & $0.80 \pm 0.1^{b}$ & $2.10 \pm 0.2^{c}$ & $73.4 \pm 2.3^{b}$ & $134.8 \pm 19^{b}$ \\
\hline & Pseudohypericin & $0.08 \mu \mathrm{M}$ & $0.94 \pm 0.1$ & $2.64 \pm 0.4^{b}$ & $79.1 \pm 6.3^{b}$ & $146.5 \pm 16$ \\
\hline & Quercetin & $10 \mu \mathrm{M}$ & $0.23 \pm 0.0^{c}$ & $2.29 \pm 0.1^{\mathrm{c}}$ & $58.8 \pm 2.4^{\mathrm{c}}$ & $116.9 \pm 12^{c}$ \\
\hline \multicolumn{7}{|c|}{$\begin{array}{l}\text { H. perforatum extract, the } 4 \text { compounds, pseudohypericin, and quercetin positive control were applied to } \\
\text { RAW } 264.7 \text { macrophages and peritoneal macrophages at concentrations shown above with } 1 \mu \mathrm{g} / \mathrm{mL} \text { LPS } \\
\text { stimulation (Compound } 1 \text { : pseudohypericin; } 2 \text { : quercetin; } 3 \text { : amentoflavone; } 4 \text { : chlorogenic acid). . The } \\
\text { release of PGE2 by RAW } 264.7 \text { cells after } 8 \mathrm{hr} \text {, by peritoneal macrophages after } 24 \mathrm{hr} \text {, and NO, TNF- } \alpha \text {, } \\
\text { and IL-1 } \beta \text { after } 24 \mathrm{hr} \text { of treatment by both cells were quantified. LPS-induced production of these } \\
\text { inflammatory mediators and cytokines is shown in absolute concentrations (mean } \pm \mathrm{SEM}, \mathrm{n}=3 \text { ). } \\
\text { Significant induction by LPS is in DMSO vehicle control treatment is indicated by }{ }^{a} \text { ( } \mathrm{p}<0.01 \text { ), and } \\
\text { significant inhibition by treatments compared to DMSO+LPS control is indicated by }{ }^{\mathrm{b}}(\mathrm{p}<0.05) \text { and }{ }^{\mathrm{c}} \\
(\mathrm{p}<0.01 \text { ). }\end{array}$} \\
\hline
\end{tabular}


Table 3

LPS-stimulated PGE2 and NO production by RAW 264.7 mouse macrophages treated with fractions of $H$. perforatum extract.

\begin{tabular}{|c|c|c|c|c|c|c|c|}
\hline \multirow{2}{*}{\multicolumn{2}{|c|}{ Treatment }} & \multirow{2}{*}{\multicolumn{2}{|c|}{ Concentration }} & \multicolumn{4}{|c|}{ Inflammatory mediator production } \\
\hline & & & & \multicolumn{2}{|c|}{ PGE2 (ng/mL) } & \multicolumn{2}{|c|}{ NO $(\mu \mathrm{M})$} \\
\hline \multirow{2}{*}{\multicolumn{2}{|c|}{$\begin{array}{l}\text { Media+DMSO } \\
H . \text { perf extract }\end{array}$}} & - & & $4.3 \pm 0.2$ & & $\mathbf{2 1 . 5} \pm 1.3$ & \\
\hline & & $58.9)$ & & $1.4 \pm 0.3$ & $* *$ & $8.4 \pm 0.4$ & $* *$ \\
\hline \multirow{11}{*}{ Fractions } & 1 & 33.2 & & $1.1 \pm 0.2$ & $* *$ & $7.1 \pm 0.6$ & $* *$ \\
\hline & 2 & 29.7 & & $1.5 \pm 0.1$ & $* *$ & $8.6 \pm 0.6$ & $* *$ \\
\hline & 3 & 6.7 & & $2.5 \pm 0.4$ & $* *$ & $11.4 \pm 1.3$ & ** \\
\hline & 4 & 1.5 & & $2.2 \pm 0.2$ & $* *$ & $10.3 \pm 1.1$ & $* *$ \\
\hline & 5 & 44.7 & $\mu \mathrm{g} / \mathrm{mL}$ & $0.8 \pm 0.1$ & $* *$ & $7.3 \pm 0.6$ & $* *$ \\
\hline & 6 & 16.5 & & $1.4 \pm 0.1$ & $* *$ & $9.5 \pm 0.4$ & ** \\
\hline & 7 & 6.7 & & $1.7 \pm 0.2$ & $* *$ & $11.8 \pm 0.6$ & $* *$ \\
\hline & 8 & 10.5 & & $3.1 \pm 0.2$ & $*$ & $14.2 \pm 0.6$ & $* *$ \\
\hline & 9 & 2.1 & & $3.0 \pm 0.2$ & $*$ & $15.7 \pm 0.9$ & $*$ \\
\hline & 10 & 23.5 & & $1.9 \pm 0.1$ & $* *$ & $\mathbf{1 0 . 5} \pm 1.3$ & $* *$ \\
\hline & 11 & $12.6)$ & & $1.2 \pm 0.2$ & $* *$ & $7.3 \pm 1.1$ & $* *$ \\
\hline \multicolumn{2}{|c|}{ Quercetin } & 10 & $\mu \mathrm{M}$ & $0.8 \pm 0.0$ & $* *$ & $6.4 \pm 1.0$ & $* *$ \\
\hline
\end{tabular}

H. perforatum extract and its fractions at concentrations in proportion to their yield in the fraction were applied to RAW 264.7 macrophages with $1 \mu \mathrm{g} / \mathrm{mL}$ LPS stimulation. Cell culture supernatant level of inflammatory mediators PGE2 and NO after $8 \mathrm{~h}$ and $24 \mathrm{~h}$ treatment (Mean $\pm \mathrm{SEM}, \mathrm{n}=3$ ) are shown. * and $* *$ indicate significant $(\mathrm{p}<0.05$ and $\mathrm{p}<0.01)$ difference compared to media+DMSO vehicle control. 
Table 4

LPS-stimulated PGE2 and NO production by RAW 264.7 mouse macrophages treated with fractions of $H$. gentianoides extract

\begin{tabular}{|c|c|c|c|c|c|c|c|}
\hline \multirow{2}{*}{\multicolumn{2}{|c|}{ Treatment }} & \multirow{2}{*}{\multicolumn{2}{|c|}{ Concentration }} & \multicolumn{4}{|c|}{ Inflammatory mediator production } \\
\hline & & & & \multicolumn{2}{|c|}{ PGE2 (ng/mL) } & \multicolumn{2}{|c|}{ NO $(\mu \mathrm{M})$} \\
\hline \multirow{2}{*}{\multicolumn{2}{|c|}{$\begin{array}{l}\text { Media+DMSO } \\
\text { H. genti extract }\end{array}$}} & - & & $2.7 \pm 0.4$ & & $\mathbf{1 5 . 5} \pm 1.3$ & \\
\hline & & 48.5 & & $\mathbf{1 . 0} \pm 0.1$ & $* *$ & $9.9 \pm 0.5$ & $* *$ \\
\hline \multirow{10}{*}{ Fractions } & 1 & 176 & & $2.7 \pm 0.4$ & & $9.1 \pm 1.6$ & $* *$ \\
\hline & 2 & 75.1 & & $1.7 \pm 0.2$ & $* *$ & $7.3 \pm 0.9$ & $* *$ \\
\hline & 3 & 25.5 & & $\mathbf{1 . 5} \pm 0.2$ & $* *$ & $\mathbf{5 . 6} \pm 0.3$ & $* *$ \\
\hline & 4 & 13.4 & & $\mathbf{1 . 4} \pm 0.2$ & $* *$ & $13.8 \pm 0.8$ & \\
\hline & 5 & 6.1 & $\mu \mathrm{g} / \mathrm{mL}$ & $\mathbf{2 . 0} \pm 0.4$ & $*$ & $6.8 \pm 1.4$ & $* *$ \\
\hline & 6 & 8.6 & & $1.7 \pm 0.3$ & $* *$ & $6.7 \pm 1.4$ & $* *$ \\
\hline & 7 & 13.7 & & $1.6 \pm 0.2$ & $* *$ & $7.1 \pm 1.1$ & $* *$ \\
\hline & 8 & 10.8 & & $0.2 \pm 0.0$ & $* *$ & $3.7 \pm 0.1$ & $* *$ \\
\hline & 9 & 9.3 & & $\mathbf{1 . 5} \pm 0.1$ & $* *$ & $\mathbf{6 . 8} \pm 0.9$ & $* *$ \\
\hline & 10 & 6.8 & & $2.6 \pm 0.5$ & & $12.2 \pm 1.9$ & $*$ \\
\hline \multicolumn{2}{|c|}{ Quercetin } & 10 & $\mu \mathrm{M}$ & $\mathbf{0 . 6} \pm 0.1$ & $* *$ & $\mathbf{5 . 7} \pm 0.6$ & $* *$ \\
\hline
\end{tabular}

H. gentianoides extract and its fractions at concentrations in proportion to their yield in the fraction were applied to RAW 264.7 macrophages with $1 \mu \mathrm{g} / \mathrm{mL}$ LPS stimulation. Cell culture supernatant level of inflammatory mediators PGE2 and NO after $8 \mathrm{~h}$ and $24 \mathrm{~h}$ treatment (Mean $\pm \mathrm{SEM}, \mathrm{n}=3$ ) are shown. * and

$* *$ indicate significant $(\mathrm{p}<0.05$ and $\mathrm{p}<0.01)$ difference compared to media+DMSO vehicle control. 
Table 5

LPS-stimulated inflammatory mediator and cytokine release by RAW 264.7 mouse macrophages treated with H. gentianoides extract, fractions and uliginosin A

\begin{tabular}{|c|c|c|c|c|c|c|}
\hline \multicolumn{2}{|c|}{ Treatments } & Concentration & PGE2 & NO & TNF- $\alpha$ & IL-1及 \\
\hline & & & \multicolumn{4}{|c|}{ Levels in supernatant $($ mean $\pm S E M)$} \\
\hline \multirow{2}{*}{\multicolumn{2}{|c|}{ Media+DMSO }} & & $\mathrm{ng} / \mathrm{mL}$ & $\mu \mathrm{M}$ & $\mathrm{ng} / \mathrm{mL}$ & $\mathrm{pg} / \mathrm{mL}$ \\
\hline & & & $0.1 \pm 0.0$ & $\mathbf{0 . 0 5} \pm 0.1$ & $0.8 \pm 0.2$ & $69 \pm 9$ \\
\hline \multicolumn{2}{|c|}{ Media+DMSO+LPS } & & $4.9 \pm 0.1^{\mathrm{a}}$ & $15.6 \pm 0.6^{\mathrm{a}}$ & $\mathbf{1 2 . 3} \pm 1.7^{\mathrm{a}}$ & $\mathbf{5 7 2} \pm 23^{\mathbf{a}}$ \\
\hline \multicolumn{2}{|c|}{ H. gentianoides extract } & $48.5 \mu \mathrm{g} / \mathrm{mL}$ & $1.2 \pm 0.3^{\mathrm{c}}$ & $10.5 \pm 0.4^{\mathrm{c}}$ & $8.1 \pm 0.5^{c}$ & $305 \pm 31^{\mathrm{c}}$ \\
\hline \multirow{3}{*}{ Fraction } & 5 & $6.1 \mu \mathrm{g} / \mathrm{mL}$ & $3.5 \pm 0.1^{\mathrm{b}}$ & $8.7 \pm 0.2^{c}$ & $11.4 \pm 0.2$ & $393 \pm 22^{c}$ \\
\hline & 8 & $10.8 \mu \mathrm{g} / \mathrm{mL}$ & $0.4 \pm 0.1^{\mathrm{c}}$ & $6.3 \pm 0.3^{c}$ & $9.3 \pm 0.4^{\mathrm{c}}$ & $248 \pm 42^{\mathrm{c}}$ \\
\hline & 9 & $9.3 \mu \mathrm{g} / \mathrm{mL}$ & $2.7 \pm 0.2^{c}$ & $8.3 \pm 0.3^{c}$ & $10.5 \pm 0.3^{b}$ & $436 \pm 29^{c}$ \\
\hline \multirow{4}{*}{ Uliginosin } & & $0.6 \mu \mathrm{M}$ & $\mathbf{4 . 5} \pm 0.2$ & $9.8 \pm 0.6^{c}$ & $10.4 \pm 0.3^{b}$ & $438 \pm 26^{c}$ \\
\hline & & $0.04 \mu \mathrm{M}$ & $4.9 \pm 0.2$ & $\mathbf{1 4 . 8} \pm 0.6$ & $11.8 \pm 0.1$ & $\mathbf{5 3 0} \pm 19$ \\
\hline & & $2.0 \mu \mathrm{M}$ & $2.0 \pm 2.1^{\mathrm{c}}$ & $8.2 \pm 0.2^{c}$ & $10.1 \pm 0.2^{b}$ & $347 \pm 47^{c}$ \\
\hline & $\zeta$ & $2.6 \mu \mathrm{M}$ & $1.8 \pm 0.3^{c}$ & $7.7 \pm 0.2^{c}$ & $10.8 \pm 0.1^{b}$ & $332 \pm 37^{\mathrm{c}}$ \\
\hline \multicolumn{2}{|c|}{ Quercetin } & $10 \mu \mathrm{M}$ & $0.9 \pm 0.1^{\mathrm{c}}$ & $4.0 \pm 0.3^{c}$ & $5.9 \pm 0.5^{c}$ & $399 \pm 33^{\mathrm{c}}$ \\
\hline
\end{tabular}

H. gentianoides extract, three of its fractions, uliginosin A, and quercetin positive control were applied to RAW 264.7 macrophages at concentrations shown above with $1 \mu \mathrm{g} / \mathrm{mL}$ LPS. Production of PGE2 after 8 $\mathrm{hr}$, as well as NO, TNF- $\alpha$, and IL-1 $\beta$ after $24 \mathrm{hr}$ of treatment were quantified. LPS-induced production of these inflammatory mediators and cytokines is shown in absolute concentrations (mean $\pm \mathrm{SEM}, \mathrm{n}=3$ ). Significant induction by LPS is indicated by ${ }^{a}(\mathrm{p}<0.01)$, and significant inhibition by treatments compared to DMSO+LPS control are indicated by ${ }^{\mathrm{b}}(\mathrm{p}<0.05)$ and ${ }^{\mathrm{c}}(\mathrm{p}<0.01)$. 